\title{
Characteristics of traumatic brain injury patients with abnormal neuroimaging in Southeast Norway
}

\author{
Cathrine Tverdal ${ }^{1,2^{*}}$ (D), Mads Aarhus ${ }^{1}$, Nada Andelic ${ }^{3,4}$, Ola Skaansar ${ }^{1,2}$, Karoline Skogen $^{5}$ and Eirik Helseth ${ }^{1,2}$
}

\begin{abstract}
Background: The vast majority of hospital admitted patients with traumatic brain injury (TBI) will have intracranial injury identified by neuroimaging, requiring qualified staff and hospital beds. Moreover, increased pressure in health care services is expected because of an aging population. Thus, a regular evaluation of characteristics of hospital admitted patients with TBI is needed. Oslo TBI Registry - Neurosurgery prospectively register all patients with TBI identified by neuroimaging admitted to a trauma center for southeast part of Norway. The purpose of this study is to describe this patient population with respect to case load, time of admission, age, comorbidity, injury mechanism, injury characteristics, length of stay, and 30-days survival.
\end{abstract}

Methods: Data for 5 years was extracted from Oslo TBI Registry - Neurosurgery. Case load, time of admission, age, sex, comorbidity, injury mechanism, injury characteristics, length of stay, and 30-days survival was compiled and compared.

Results: From January 1st, 2015 to December 31st, 2019, 2153 consecutive patients with TBI identified by neuroimaging were registered. The admission rate of TBI of all severities has been stable year-round since 2015 . Mean age was 52 years (standard deviation 25, range 0-99), and 68\% were males. Comorbidities were common; $28 \%$ with pre-injury ASA score of $\geq 3$ and $25 \%$ used antithrombotic medication. The dominating cause of injury in all ages was falls (55\%) but increased with age. Upon admission, the head injury was classified as mild TBI in 46\%, moderate in $28 \%$, and severe (Glasgow coma score $\leq 8$ ) in $26 \%$. Case load was stable without seasonal variation. Majority of patients (68\%) were admitted during evening, night or weekend. 68\% was admitted to intensive care unit. Length of hospital stay was 4 days (median, interquartile range 3-9). 30-day survival for mild, moderate and severe TBI was 98, 94 and 69\%, respectively.

Conclusions: The typical TBI patients admitted to hospital with abnormal neuroimaging were aged 50-79years, often with significant comorbidity, and admitted outside ordinary working hours. This suggests the necessity for allhour presence of competent health care professionals.

Keywords: Traumatic brain injury, Neurosurgery, Trauma center, Hospital admission

\footnotetext{
*Correspondence: uxtvec@ous-hf.no; cathrinebt@gmail.com

'Department of Neurosurgery, Ullevål Hospital, Oslo University Hospital, P. O.

Box 4956 Nydalen, N-0424 Oslo, Norway

${ }^{2}$ Institute of Clinical Medicine, Faculty of Medicine, University of Oslo, Oslo,

Norway

Full list of author information is available at the end of the article
}

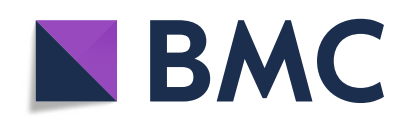

(c) The Author(s). 2020 Open Access This article is licensed under a Creative Commons Attribution 4.0 International License, which permits use, sharing, adaptation, distribution and reproduction in any medium or format, as long as you give appropriate credit to the original author(s) and the source, provide a link to the Creative Commons licence, and indicate if changes were made. The images or other third party material in this article are included in the article's Creative Commons licence, unless indicated otherwise in a credit line to the material. If material is not included in the article's Creative Commons licence and your intended use is not permitted by statutory regulation or exceeds the permitted use, you will need to obtain permission directly from the copyright holder. To view a copy of this licence, visit http://creativecommons.org/licenses/by/4.0/. The Creative Commons Public Domain Dedication waiver (http://creativecommons.org/publicdomain/zero/1.0/) applies to the data made available in this article, unless otherwise stated in a credit line to the data. 


\section{Background}

Traumatic Brain Injury (TBI) is globally recognized as a major health and socioeconomic issue (James et al. 2019). TBI is defined as alteration in brain function, or other evidence of brain pathology, caused by an external force (Menon et al. 2010). The definition is wide, and the term TBI represents a heterogeneous group of patients.

The international incidence of TBI in a general population is estimated as high as 369-790/100000 (James et al. 2019; Feigin et al. 2013), the vast majority being minimal and mild TBIs. Narrowing down to hospital admitted TBI, the incidence rate in high-income countries drops to $83-262 / 100000$, with increasing fractions of moderate and severe TBIs (Peeters et al. 2015; Pedersen et al. 2015; Koskinen and Alaranta 2008; Rickels et al. 2010; Heskestad et al. 2009; Andelic et al. 2008; Centers for Disease Control and Prevention 2019). Refining it even further to hospital admitted patients with abnormal traumatic intracranial findings on computed tomography (CT), the incidence rate in Scandinavian countries drops to 26-42/100000 (Pedersen et al. 2015; Heskestad et al. 2009; Andelic et al. 2008).

If head-injured patients are triaged according to established guidelines, the vast majority admitted to hospital will have TBI identified by neuroimaging (Sollid et al. 2008; Unden et al. 2013; National Institute for Health and Care Excellence 2014; Pandor et al. 2011). With guideline compliance, these patients will represent the majority of hospital admitted TBI patients in present and near future.

To describe this group of TBI patients, the Department of Neurosurgery at Oslo University Hospital (OUH) established in 2015 the Oslo TBI Registry Neurosurgery for admitted patients with TBI identified by neuroimaging (Fig. 1). The registry includes information about patient characteristics, injury mechanism, neuroimaging findings, neurosurgical interventions, length of stay, discharge status, post discharge destination, and 30-day survival. The overall registry's purpose is to optimize patient management and adequately delegate the use of hospital resource.

In trauma care organizations, hospital resources include adequate and qualified staff, staffed operating theaters, access to imaging, available beds and support services. Hence, for in hospital resource planning accurate information on patient load, patient characteristics, injury severity and time of admittance is of great importance. Several studies have shown the number of admissions for trauma patients increases on weekends, in the evenings, and are subject to seasonal variation (Kieffer et al. 2016; Robertson and Giannoudis 2004; Stonko et al. 2018; Vaziri et al. 2007; Ali and Willett 2015; Rising et al. 2006; Roislien et al. 2018). We wanted to study

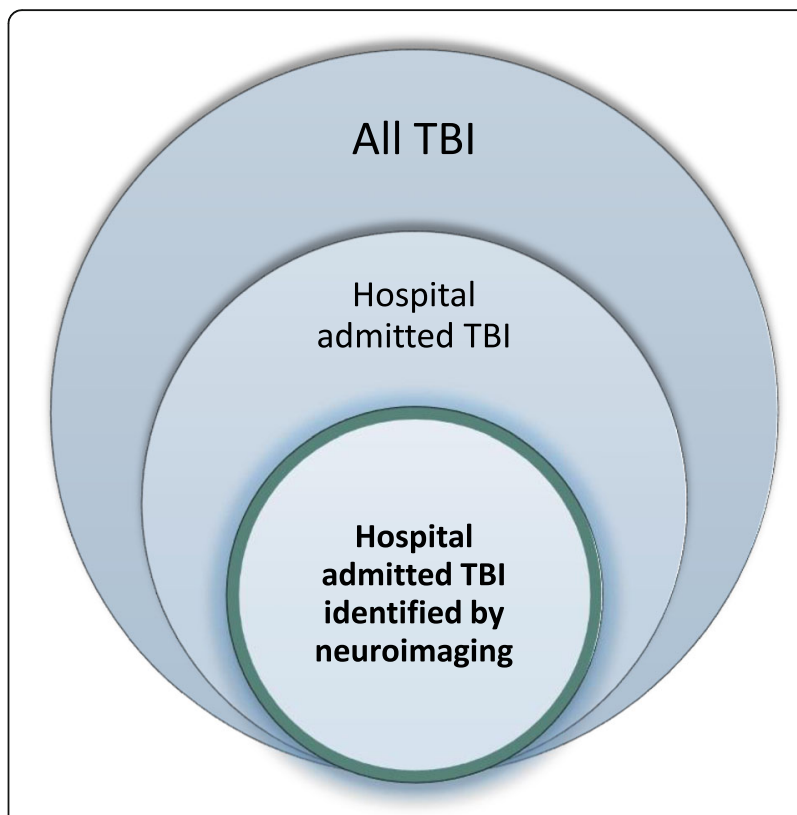

Fig. 1 Illustration of the patient population with TBI included in the Oslo TBI Registry - Neurosurgery. The patient population with TBI in the South East health region, only patients with verified TBI on neuroimaging and admitted to $\mathrm{OUH}$ are included in the Oslo TBI Registry - Neurosurgery

the extent this is applicable to TBI patients. The study may be of international interest as Norway has a wellorganized public trauma system with a highly developed infrastructure and transportation systems enabling TBI patients to be transported to the trauma centers as well as well-equipped trauma teams in centers for definitive treatment of patients (Sollid et al. 2008).

The aim for this study was to describe this patient population with respect to case load, time of admission, seasonal variations, age, sex, comorbidity, injury mechanism, type and severity of TBI, length of hospital stay and 30-day survival.

\section{Methods \\ Study design}

A descriptive study of TBIs, identified by neuroimaging, admitted to Oslo University Hospital (OUH) in the time period January 1st, 2015 to December 31st, 2019.

\section{Study setting}

Norway has a population of 5.3 million, the mainland covers $323,781 \mathrm{~km}^{2}$, and is divided into four geographical healthcare regions. The South-East region is the largest with a population of 3,032,670 in 2019 (Statistics Norway n.d.) and covers $110,000 \mathrm{~km}^{2}$ with urban and rural areas. The region encompasses 19 local hospitals that provide acute care and general surgical assessment, management and stabilization (Helse og omsorgsdepartementet 2017). 
Oslo University Hospital (OUH) is the only Level I trauma center with neurosurgical services in the region. $\mathrm{OUH}$ also serves as the primary trauma referral hospital for Oslo, with a population of 693,491 in 2019 (Statistics Norway n.d.). Norway provides universal healthcare to all Norwegian residents.

Trauma patients with severe injuries or suspected severe TBI are transported directly and admitted to OUH. The remaining trauma patients are admitted to local hospitals for management and only transferred to $\mathrm{OUH}$ if deemed necessary. Treatment of severe TBI at OUH follows the Brain Trauma Foundation guideline (Ronning et al. 2018; Sovik et al. 2014; Brain Trauma Foundation 2016). Minimal, mild and moderate TBI patients are managed according to the Scandinavian guidelines for initial management of minimal, mild and moderate head injuries in adults and in children (Astrand et al. 2016; Unden et al. 2013).

\section{Database}

The Oslo TBI Registry - Neurosurgery is a quality control database run by the neurosurgical department at OUH since January 1st, 2015. The Neurosurgeons registered patients prospectively on daily basis and a dedicated group collected data for each patient (CT, OS, $\mathrm{EH})$. Data is retrieved from electronic medical records and stored in Medinsight (version 2.12.4.0), a database approved by the OUH data protection officer. Medinsight is linked to the National Population Register and date of death is automatically updated. Inclusion criteria are: (a) traumatic brain injury; (b) cerebral-CT/CTA or cerebral-MRI/MRA with findings of acute trauma (hemorrhage, fracture, traumatic axonal injury, vascular injury); (c) admitted to OUH within 7 days post-injury; (d) having a Norwegian social security number. Data for this study was retrieved from the Oslo TBI Registry Neurosurgery on February 17th, 2020.

\section{Variables}

\section{Demographic factors}

Age was retrieved as a continuous variable and categorized into five-year intervals. Sex was registered as male or female. Living status at time of injury is registered into home - independent, home - with assistance, or institutionalized.

\section{Comorbidity}

Pre-injury health status was assessed using three different categories: (i) American Society of Anesthesiologists ASA Physical Status Classification System (ASA1: normal healthy; ASA2: mild systemic disease; ASA3: severe systemic disease; ASA4: severe systemic disease that is a constant threat to life) (American Society of Anesthesiologists 2014); (ii) use of anticoagulation/antiplatelet medication (none, antiplatelet, anticoagulation, both antiplatelet and anticoagulation); (iii) prior substance dependence previously documented in medical records (yes/no).

\section{Trauma mechanism}

Trauma mechanism was grouped into (i) falls; (ii) motor vehicle crashes (MVC) (including motor cycles, ATV and snowmobile); (iii) pedestrian hit by a motor vehicle; (iv) bicycle (including electric bicycles and scooters) (v) sports; (vi) violence; (vii) self-harm; (viii) other or unknown. High energy as yes/no ("yes"; fall from height $\geq$ $3 \mathrm{~m}, \mathrm{MVC}$, bicycle, or when high-energy was described; e.g. downhill skiing). Alcohol influence at time of injury as yes/no ("yes"; either positive blood alcohol level or description of alcohol intake before injury).

\section{Neuroimaging}

Cerebral-CT was done as part of the primary assessment and an additional cerebral-MRI was only performed on clinical indication. The following traumatic imaging findings were registered (yes/no); cranial fracture, epidural hematoma $(E D H)$, acute subdural hematoma $(\mathrm{SDH})$, traumatic subarachnoid hemorrhage (tSAH), intraventricular hemorrhage (IVH), brain contusion, traumatic axonal injury (TAI), and penetrating injury. The Rotterdam CT score was used to classify CT findings and was assessed on the initial cerebral-CT with a range from 1 to 6 (worst score $=6$ ). The score is based on (i) status of basal cisterns (normal, compressed, or absent); (ii) midline shift $(0-5 \mathrm{~mm}$ or $>5 \mathrm{~mm})$; (iii) epidural hematoma (present or absent); (iv) traumatic subarachnoid hemorrhage/intraventricular hemorrhage (present or absent). Increased Rotterdam CT score correlates with increased mortality in patients with severe and moderate TBI (Maas et al. 2005).

\section{Injury severity}

The Glasgow coma score (GCS) recorded was the lowest score documented in the time window between injury and arrival at the OUH emergency room (ER) or intubation. TBI was categorized according to Head Injury Severity Score (HISS) into minimal (GCS 15 and no loss of consciousness or amnesia), mild (GCS 14 or 15 plus amnesia, or brief $(<5 \mathrm{~min})$ loss of consciousness, or impaired alertness or memory), moderate (GCS $9-13$ or loss of consciousness $\geq 5 \mathrm{~min}$ or focal neurological deficit) or severe (Severe: GCS $\leq 8$ ) (Stein and Spettell 1995). In the analysis, minimal TBI with traumatic findings on CT was grouped with mild TBI. In the literature, mild TBI with traumatic findings on CT is referred to as complicated mild TBI (Williams et al. 1990; Iverson et al. 2012). 
Multiple trauma was defined as injuries to other parts of the body verified by imaging (skeletal fractures or injury to internal organs) and registered with "no", "yes, conservative treatment" or "yes, surgical treatment". Skin injuries were not registered.

\section{Hospital admission}

Time and date of admission to OUH was registered and from what location (i) scene of accident; (ii) local hospital; (iii) Oslo Emergency Department (separate location from the main hospital); (iv) other. The presence of OUH trauma team (yes/no), which consists of specialty trained physicians and nurses in anesthesia and surgery, radiologist, radiographer and bioengineer. Monday to Friday between 07:00 and 17:00 the hospital is staffed to manage elective and emergency patients, and critically ill inpatients. Beyond these hours, the hospital is mainly staffed for emergencies and care of critically ill inpatients.

All patients admitted to an intensive care unit (ICU) were registered as admitted to ICU regardless of medical condition. In addition, patients admitted to an intermediate unit and in need of any organ-supportive interventions/medication or sedatives, or requiring observation > $24 \mathrm{~h}$, was registered as ICU admitted. Length of stay (LOS) was calculated with formula $L O S=$ date of discharge - date of admission +1 . Stay at rehabilitation unit was not included in calculation of LOS.

\section{Statistical analysis}

Descriptive statistics summarize the characteristics of patients, injuries and treatment. Categorical data is presented with frequencies and percentages. Continuous variables are presented with mean (standard deviation; $\mathrm{SD})$ or median (interquartile range; IQR) depending on distribution. To compare group differences, we used Pearson $\chi^{2}$ test for categorical variables, and independent $t$-test or Mann-Whitney $U$ Test for continuous variables. 30-days survival was estimated using Kaplan-Meier and log-rank test for group comparison. Two-sided $p$-values of 0.05 were considered for statistical significance. Data were analyzed using IBM SPSS $\odot$ version 25.

\section{Ethical considerations}

Anonymized data was retrieved from the Oslo TBI Registry. The Registry was approved by OUH data protection officer (approval number 2016/17569). This study qualifies as a quality control study, hence application to the regional ethical committee was waived (Regional Committees for Medical and Health Research Ethics (REC), 2012). The study was approved by OUH data protection officer (approval number 18/20658).

\section{Results}

During the five-year study period 2153 consecutive patients with TBI identified by neuroimaging were admitted to OUH and included in this study.

TBI was seen in all age groups and peaked in the age groups between 55 years and 74 years (Fig. 2a); mean age was 52 years (SD 25, range 0-99). There was a clear male preponderance (68\%), especially in younger patients. The male dominance was gradually reduced with increasing age. Median male age was 54 years (mean 50, SD 23), median female age was 63 (mean 57, SD 27) (Mann-Whitney $U$ Test, $p=<.001$ ). The majority lived independently at home (88\%) (Table 1, Fig. 2b).

Description of comorbidity measured by ASA-PS score, use of antithrombotic medication and substance dependency are given in Table 1 and Figs. 2c-e. In the younger TBI age group the vast majority had an ASA-PS score of 1 or 2 . The landscape changed in the elderly group with larger fractions not living independently, and ASA-PS score of 3 or 4 (Fig. 2c). The overall use of antithrombotic medication was $25 \%$, increasing with age with a proportion of $42 \%$ in age $\geq 50$ (Fig. 2d). Preinjury substance dependence was registered in $15 \%$ and was spread throughout all adult age groups, but most prevalent in middle aged males (Fig. 2e). Alcohol accounted for $9 \%$ alone.

Trauma mechanism is presented in Table 1 and Fig. 3. Falls were the dominating cause of injury (55\%) in all age groups, except patients aged 10-19 years where MVC accounted for $26 \%$, sports $22 \%$ and falls $19 \%$. The fraction of fall injuries increased with age, especially in patients' $\geq 50$ years (Fig. 3a). High-energy trauma was seen in 812/2153 (38\%) with a mean age of 43 years (SD 22 ), in low-energy trauma mean age was 58 years (SD 24) (CI 95\% 13-17, $p=<.001$ ). At time of injury 579/ 2153 (27\%) were under influence of alcohol with a mean age of 49 years (SD 18), patients not influenced by alcohol had mean age 53 years (SD 27) (CI 95\% 2.5-6.4, $p=<.001)$. The percentage of patients influenced by alcohol was $>30 \%$ in age group $20-75$ years. No patients $<15$ years was influenced by alcohol (Fig. 3b). Males were more often influenced by alcohol (31\%) than women $(19 \%)\left(\mathrm{X}^{2}(1)=34, p=<.001\right)$.

Severity of TBI and TBI pathology is presented in Table 2. Median GCS was 13 (IQR 8-15). TBI severity according to HISS was minimal $6 \%$, mild $40 \%$, moderate $28 \%$ and severe $26 \%$. When comparing age groups and HISS, mild TBI was more frequent in the youngest and oldest age groups, severe TBI peaked in age group 1019 years (39\%) and gradually decreased with age ( $\chi 2$ (18) $=60, p=<.001)$. There was no difference in HISS between male/female $\left(\chi^{2}(2)=4, p=.1\right)$.

Rotterdam CT score $\geq 4$ was seen in 362/2153 (17\%). Compressed/absent basal cisterns were seen 


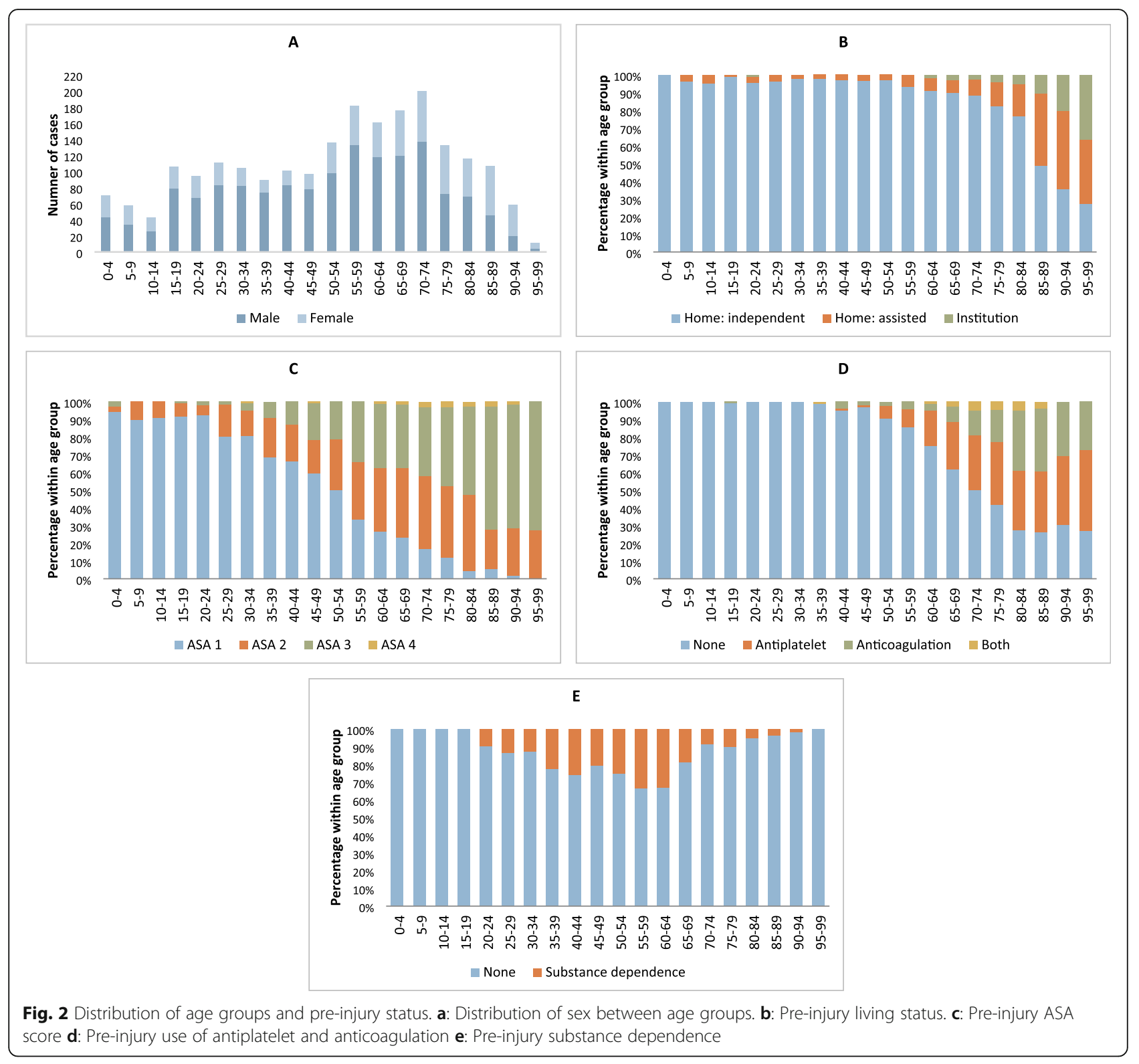

in $352(16 \%)$ and midline shift $\geq 5 \mathrm{~mm}$ and $353 / 2153$ (17\%). The most frequent pathologies in this series were $\mathrm{SDH}, \mathrm{tSAH}$, brain contusion and cranial fracture. Multiple pathologies were seen in the majority (70\%), e.g. simultaneous cranial fracture, SDH, $\mathrm{tSAH}$ and brain contusion. Higher age was significantly associated with SDH $(p=<.001), \mathrm{tSAH}(p=<.001)$ and cranial fracture $(p=<.001)$. Younger age was associated with $\mathrm{EDH}(p=<.001)$. Penetrating injury rarely occurred (1.6\%). MRIs were done in 626/2153 (29\%) and accounted for younger patients, mean age 39 (SD 23) compared to those without MRI, mean age 58 years (SD 23) (CI 95\% 16-20, $p=<.001$ ). MRI revealed TAI lesions in 322 patients of MRIs performed (51\%).
Multiple traumas were diagnosed in 1016/2153 (47\%) with a mean age of 51 years (SD 22), compared to a mean age of 53 (SD 26) in those with isolated TBI (CI $95 \% 0.3-4, p=.03)$. The most frequent body regions affected in multitraumas were face $(24 \%)$, thoracic $(21 \%)$, extremities (14\%) and cervical spine (12\%), presented in Table 3. Spinal cord injury was present in $35 / 2153$ (1.6\%); 21 cervical and 14 thoracolumbar.

$800 / 2153$ (37\%) were transported directly from scene of accident to OUH. Before transfer to OUH 816/2153 (38\%) had primary assessment at local hospital, and 256/ $2153(24 \%)$ had primary assessment at the Oslo Emergency Department. The OUH trauma team was activated in $1656 / 2153(77 \%)$ patients with a mean age of 49 years (SD 24) compared to patients admitted without the 
Table 1 Comorbidity and injury mechanism

\begin{tabular}{ll}
\hline & N (\%) \\
\hline Male & $2153(100)$ \\
Preinjury status & $1466(68)$ \\
ASA 1. Healthy & \\
ASA2. Mild systemic disease & $975(45)$ \\
ASA 3. Severe systemic disease & $572(27)$ \\
ASA 4. Life-threatening systemic disease & $582(27)$ \\
Living home - independent & $24(1)$ \\
Living home - with assistance & $1883(88)$ \\
Institutionalized & $192(9)$ \\
Substance dependency & $51(2)$ \\
Antiplatelet & $325(15)$ \\
Anticoagulation & $322(15)$ \\
Antiplatelet and anticoagulation & $189(9)$ \\
Influenced by alcohol at time of injury & $34(1.5)$ \\
Trauma mechanism & $579(27)$ \\
High-energy trauma (Yes) & \\
Falls & $812(38)$ \\
Motor vehicle crashes & $1187(55)$ \\
Bicycle & $205(10)$ \\
Violence & $196(9)$ \\
Sports (except bicycle) & $154(7)$ \\
Self-harm & $114(5)$ \\
Other/unknown & $152(7)$ \\
\hline
\end{tabular}

trauma team who had a mean age of 61 years (SD 25) (CI 95\% 9-14, $p=<.001$ ).

LOS in hospital and ICU are presented in Table 4. On average 9.0 TBI patients were hospitalized each day during the study period, and 5.4 of them were in the ICU. ICU admission was registered in $68 \%$, these patients was slightly younger; mean age 50 years (SD 24), compared to patients not admitted ICU; 56 years (SD 25) (CI 95\% 3-8, $p=<.001$ ). Of patients with severe TBI; $96 \%$ were admitted to ICU, with ICU-LOS median 3 days (IQR 2-8).

Patient load according to year, month, day of the week and time of day is presented in Fig. 4a-c. Mean annual number was 431 (SD 38, range 384-480) (Fig. 4a) and mean monthly number was 36 (SD 2, range 17-49) (Fig. 4b). Saturday and Sunday had the highest number of admissions; 34\% (740/2153) (Fig. 4c). During the five-year period there was no significant variation in patient load per month ( $\left.\chi^{2}(44)=58, p=.08\right)$, distribution of TBI severity according to HISS per month $\left(\chi^{2}(22)=23, p=.4\right)$ or HISS per day of the week ( $\left.\chi^{2}(12)=9, p=.7\right)$. There was no significant variation of multitrauma between days of the week ( $\left.\chi^{2}(6)=9, p=.2\right)$.

The lowest admission rate during the day was in the morning at 06:00 (Fig. 4d). Admission rate gradually increased during morning and early afternoon and peaked around 14:00. The admittance continued at a high rate to midnight, declined a little after midnight and further declined after 04:00. During the whole week, significantly more TBI patients were admitted between 17:00 and 07:00 ( $\left.\chi^{2}(6)=15, p=.02\right)$. In weekends, significantly more patients were admitted during night, especially from midnight to 06:00 Saturday and Sunday ( $x^{2}(3)=$ $59, p=<.001$ ) (Fig. 4e). Overall, $68 \%$ of the patients were admitted during evening, night or weekend.

Survival estimates are presented in Fig. 5a-c. 30-day survival for mild, moderate and severe TBI was 98, 94 and $69 \%$, respectively $(p=<.001)$ (Fig. 5a). Figure 5b-c further shows how age is associated significantly with survival $(p=<.001)$. For patients with severe TBI and $<$ 60 years, most deaths occurred within 1 week after injury and 30-day survival was between 78 and 79\%, except patients 10-19years who had highest 30-days survival; $90 \%$. There was a decline in survival from 60 year olds (66\%), down to $11 \%$ in 90 year olds (Fig. 5c). The

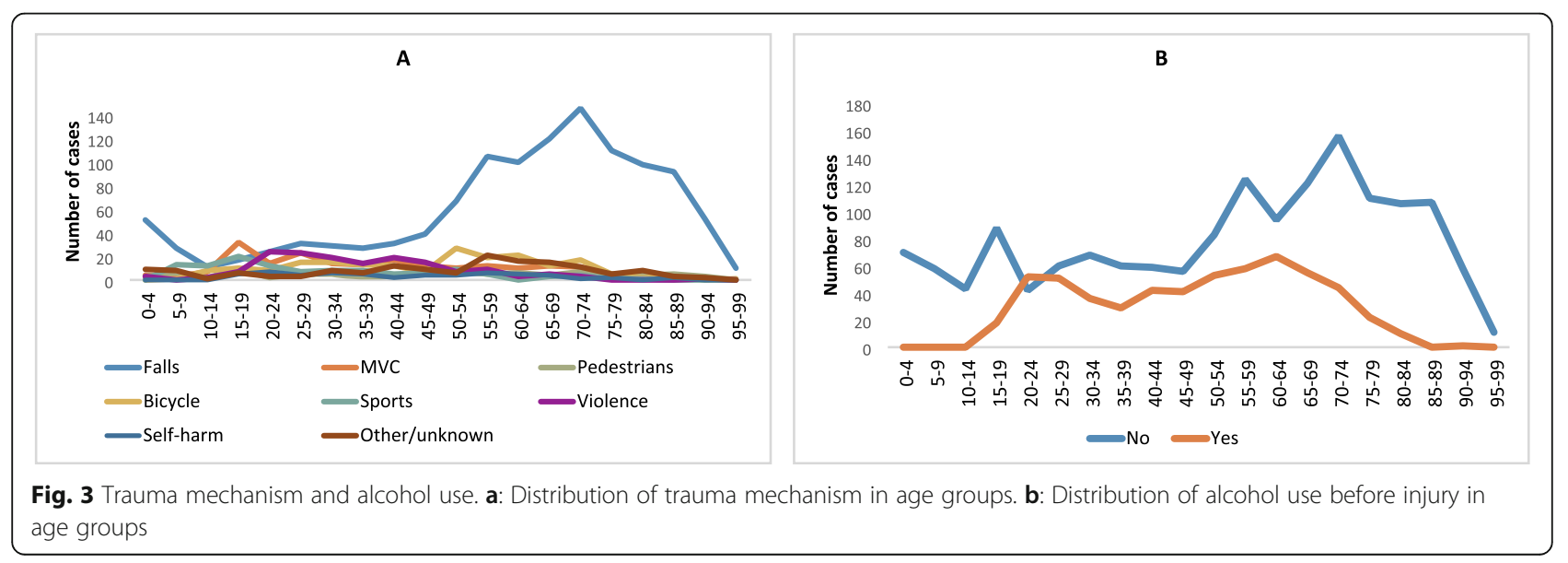


Table 2 Severity of TBI and TBI pathology

\begin{tabular}{|c|c|}
\hline & $\begin{array}{l}N(\%) \\
2153(100)\end{array}$ \\
\hline \multicolumn{2}{|l|}{ Glasgow coma score } \\
\hline $14-15$ & $1031(48)$ \\
\hline $9-13$ & $571(27)$ \\
\hline $6-8$ & $250(12)$ \\
\hline $3-5$ & $301(14)$ \\
\hline \multicolumn{2}{|l|}{ Head injury severity score } \\
\hline Minimal & $129(6)$ \\
\hline Mild & $857(40)$ \\
\hline Moderate & $612(28)$ \\
\hline Severe & $555(26)$ \\
\hline \multicolumn{2}{|l|}{ Rotterdam CT score } \\
\hline $1-2$ & 849 (39) \\
\hline $3-4$ & $1122(52)$ \\
\hline $5-6$ & $182(9)$ \\
\hline \multicolumn{2}{|l|}{ Basal cisterns } \\
\hline Normal & $1800(84)$ \\
\hline Compressed/absent & $352(16)$ \\
\hline \multicolumn{2}{|l|}{ Midline shift } \\
\hline $0-5 \mathrm{~mm}$ & $1799(84)$ \\
\hline$>5 \mathrm{~mm}$ & $353(17)$ \\
\hline \multicolumn{2}{|l|}{ Pathology seen on first $\mathrm{CT}^{\mathrm{a}}$} \\
\hline Subarachnoid hemorrhage & $1235(57)$ \\
\hline Subdural hematoma & $1185(55)$ \\
\hline Contusion & $1029(48)$ \\
\hline Epidural hematoma & $334(16)$ \\
\hline Intraventricular hemorrhage & $254(12)$ \\
\hline Skull fracture - basilar & 799 (37) \\
\hline Skull fracture - linear vault & 699 (33) \\
\hline Skull fracture - depressed vault & $122(6)$ \\
\hline Penetrating injury & $34(1.6)$ \\
\hline \multicolumn{2}{|l|}{ Traumatic Axonal Injury } \\
\hline MRI done (Yes) & $626(29)$ \\
\hline TAl lesion identified (Yes) & $322(15)$ \\
\hline
\end{tabular}

CT Computed tomography, MRI Magnetic resonance imaging, TAI Traumatic Axonal Injury

${ }^{a}$ One patient may have more than one type of traumatic injury

survival estimates include patients deemed unsalvageable upon arrival, and deaths occurring after discharge from $\mathrm{OUH}$.

\section{Discussion}

This is one of very few large-sample size studies that describes the TBI population admitted to trauma hospital from 2015 to 2019, in order to provide additional information and guide the hospital administration to
Table 3 Multiple trauma in TBI patients

\begin{tabular}{ll}
\hline & $N(\%)$ \\
& $2153(100)$ \\
\hline Multiple trauma (any) & $1016(47)$ \\
Injury present and treatment given ${ }^{\text {a }}$ & \\
Face & $517(24)$ \\
Conservative & $356(17)$ \\
Surgical & $161(7)$ \\
Cervical fx ${ }^{b}$ & $263(12)$ \\
Conservative & $225(10)$ \\
Surgical & $38(2)$ \\
Thoracic & $460(21)$ \\
Conservative & $308(14)$ \\
Surgical & $152(7)$ \\
Thoracolumbar fx & $189(9)$ \\
Conservative & $145(7)$ \\
Surgical & $44(2)$ \\
Abdominal & $124(6)$ \\
Conservative & $87(4)$ \\
Surgical & $37(2)$ \\
Pelvic fx & $101(5)$ \\
Conservative & $61(3)$ \\
Surgical & $40(2)$ \\
Consemities fx & $293(14)$ \\
Surgical & $109(5)$ \\
One pative & $184(9)$ \\
\hline
\end{tabular}

a One patient may suffer from multiple injuries

${ }^{\mathrm{b}} \mathrm{fx}$ : fracture

adequately distribute its resources. The admission rate of TBI of all severities has been stable year-round since 2015. The largest patient group is from the late middle ages. Many of the patients are elderly with comorbidities and use of antithrombotic drugs is common. The

Table 4 Length of stay at hospital and ICU

\begin{tabular}{llllll}
\hline Year & 2015 & 2016 & 2017 & 2018 & 2019 \\
\hline & $\boldsymbol{N}=\mathbf{3 8 3}$ & $\boldsymbol{N}=\mathbf{4 3 3}$ & $\boldsymbol{N}=\mathbf{4 0 4}$ & $\boldsymbol{N}=\mathbf{4 8 1}$ & $\boldsymbol{N}=\mathbf{4 5 2}$
\end{tabular}

Total LOS in days

\begin{tabular}{|c|c|c|c|c|c|}
\hline Mean (SD) & $8.2(9)$ & $8(10)$ & $8.5(9.9)$ & $6.5(6.6)$ & $7.2(8.6)$ \\
\hline Median (IQR) & $5(3-9)$ & $4(3-9)$ & $4(3-11)$ & $4(3-7)$ & $4(3-8)$ \\
\hline Sum & 3145 & 3473 & 3412 & 3115 & 3252 \\
\hline ICU admission & $N=281$ & $N=306$ & $N=283$ & $N=299$ & $N=\mathbf{2 8 7}$ \\
\hline \multicolumn{6}{|l|}{ LOS ICU in days } \\
\hline Mean (SD) & 7 (8.6) & $7.2(9)$ & $7.6(10)$ & $5.9(7.6)$ & $6.5(8.7)$ \\
\hline Median (IQR) & $3(2-9)$ & $3(2-8)$ & $3(2-10)$ & $3(2-6)$ & $3(2-6)$ \\
\hline Sum & 1952 & 2194 & 2142 & 1750 & 1874 \\
\hline
\end{tabular}



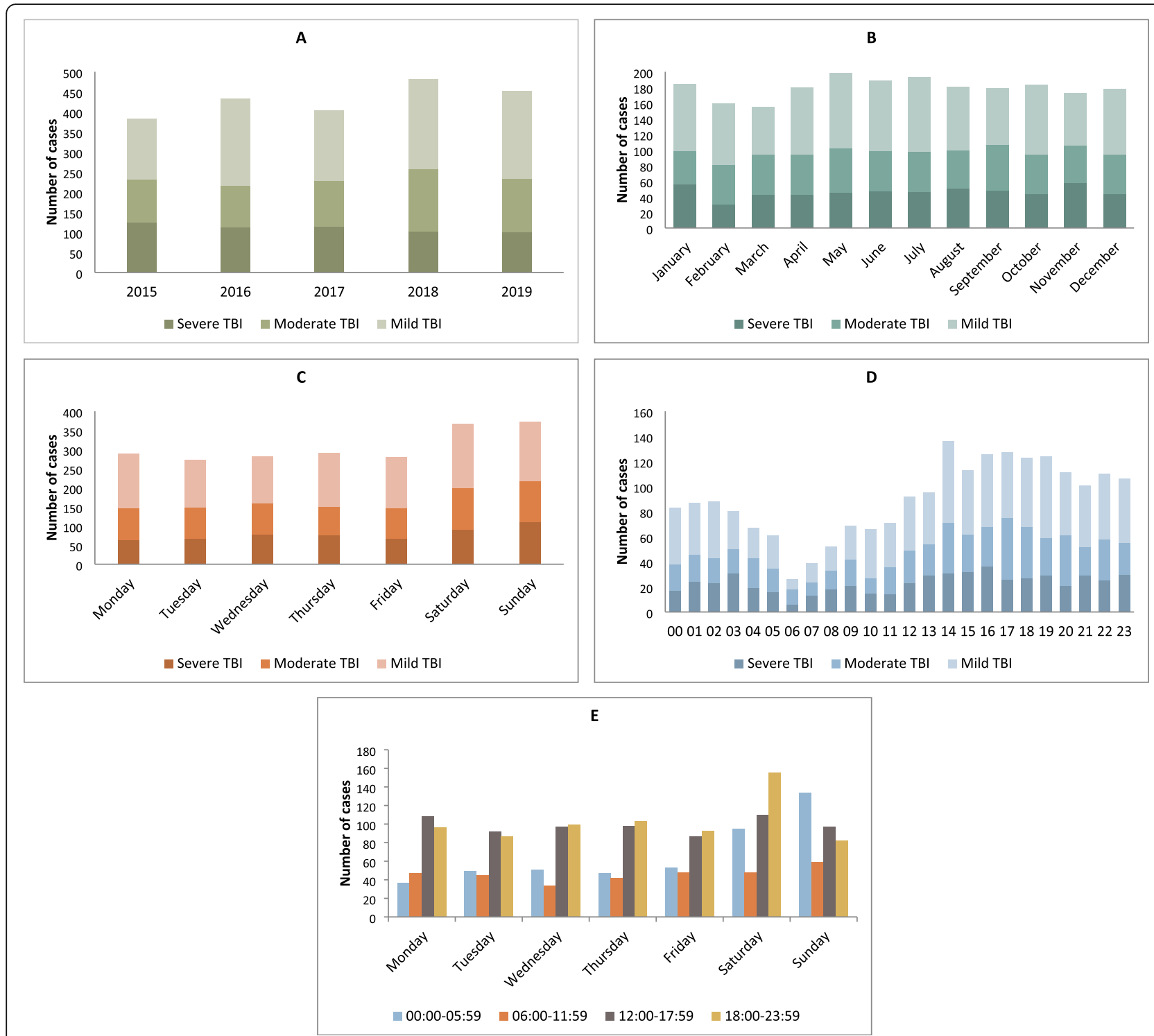

Fig. 4 Distribution of admissions in period 2015-2019. TBI severity is based on HISS. a: Admission according to year. b: Admission according to month. c: Admission according to day of the week. d: Admission according to time in hours. e: Admission according to day of the week and time-intervals in hours

majority of TBI patients were admitted when the hospital was outside ordinary working hours (Monday to Friday between 07.00 and 17:00), and $60 \%$ of the hospital stay was spent in the ICU. The TBI patients pose a significant burden to trauma hospitals due to high numbers, injury severity and complexity, need for ICU admittance, and need for all-hour presence of competent personnel.

Oslo TBI Registry - Neurosurgery had a higher mean age compared to previous epidemiological TBI studies (Peeters et al. 2015; Roozenbeek et al. 2013). However, results were in line with those from a recently published EU study from the same time period (2015 to 2017): median age 50 years (Steyerberg et al. 2019). Over the past decade, epidemiologic studies have described a shift from younger people typically injured in road crashes to increased incidence of fall injuries among the elderly in Western countries (Peeters et al. 2015; Pedersen et al. 2015; Koskinen and Alaranta 2008; Andelic et al. 2008; Roozenbeek et al. 2013; Peeters et al. 2017). Results from this study confirm this shift.

Patients with a pre-injury ASA-PS score of $\geq 3$ were substantial (28\%) compared to CENTER-TBI which was $11 \%$ (Steyerberg et al. 2019); the latter is similar to the general trauma population admitted to OUH $(10 \%)$ (Sovik et al. 2014). The more silent comorbidity; antithrombotics, were used by $42 \%$ of our TBI patients $>50$ years and this compares to other TBI studies, $33-47 \%$, 


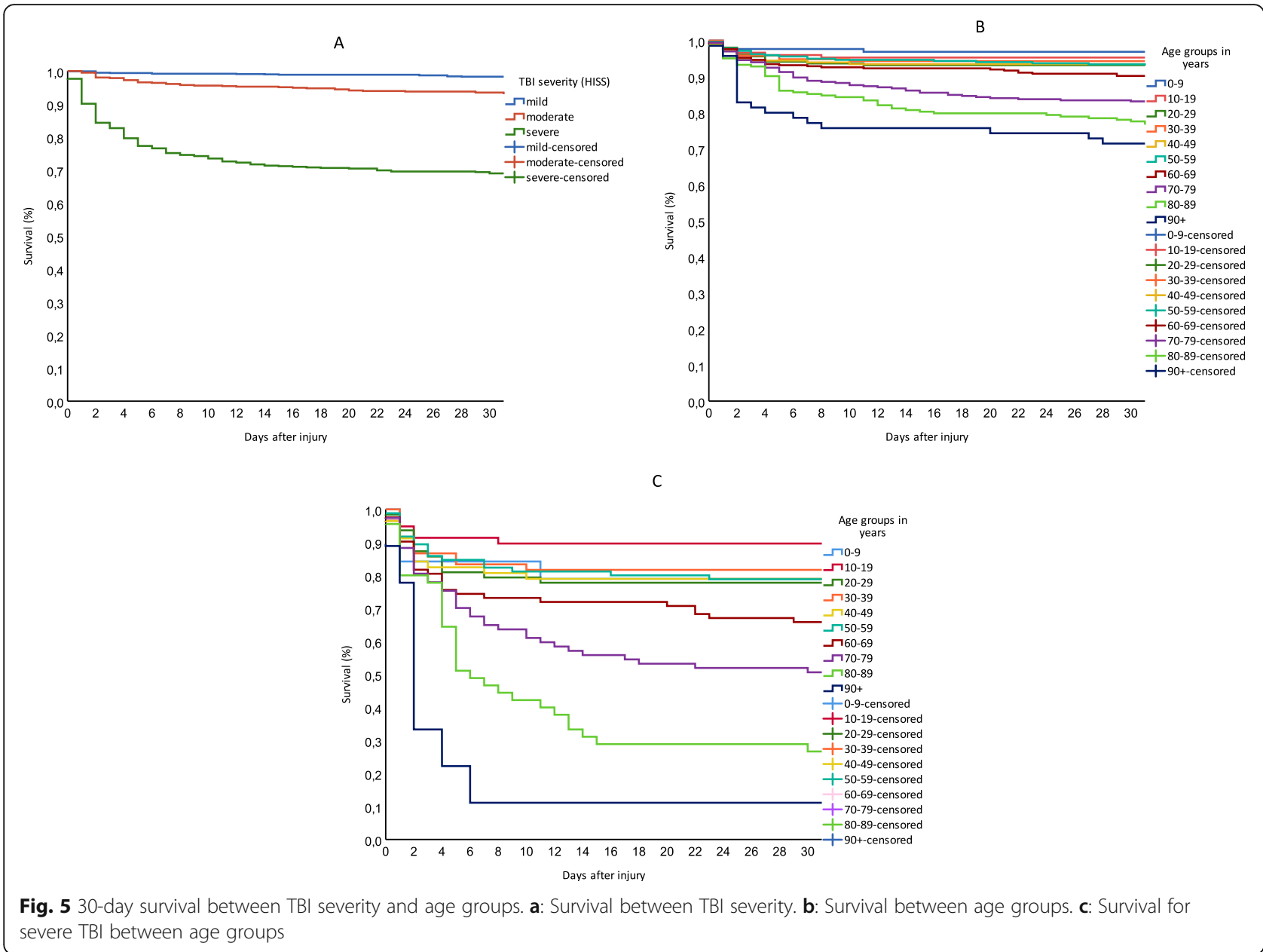

on the elderly population (Gaist et al. 2017; Julien et al. 2017; Narum et al. 2016; Lenell et al. 2019). In the total Norwegian population $18 \% \geq 40$ years use antithrombotic drugs (Berg et al. 2017) in line with previously mentioned EU study (Steyerberg et al. 2019).

Influence of alcohol at time of injury was common in all adult age groups and the overall proportion (27\%) was in line with other European and local studies reporting proportions from 24 to 36\% (Steyerberg et al. 2019; Nyholm et al. 2013; Harr et al. 2011; Owens et al. 2018; Andelic et al. 2010; Bakke et al. 2016; Bjarkø et al. 2019). In a previous study of TBI patients at OUH, 26\% reported pre-injury substance abuse when screened by CAGE questionnaire (misuse: CAGE score $\geq 2$ ), alcohol dominated (Andelic et al. 2010). Currently, no systematic assessments are made regarding substance use/dependence at admission to the hospital; hence the real proportion may be higher than our findings. The same clinical practice was found for approximately 10 years ago (Andelic et al. 2010), so the substance influence assessment at admission, preventive efforts and curative strategies need improvement.
Falls were the dominating trauma mechanism (55\%) with a marked increase from age group 50 years in line with recent studies (Steyerberg et al. 2019). The late middle-aged (50-70 years) have recently been identified as a risk group, as they intersect with increasing comorbidity on one hand and keeping up physical and social activity on the other (Gale et al. 2018; Peeters et al. 2019). Thus, fall-preventing strategies ought to include this age-group as well. Overall, we found traffic accounted for a quarter of trauma mechanism. In Norway, systematic road safety efforts since the 1970s have resulted in a sharp reduction in road traffic deaths. However, the risk for injuries is higher for cyclists compared to drivers (Injuries in Norway, 2017). This is reflected in our study, the proportion of bicycle crashes was similar to MVC, and should be in focus of preventive efforts in the future.

In the entire TBI population it is estimated that 80 90\% sustains mild TBI (Feigin et al. 2013; National Institute for Health and Care Excellence 2014). Our study population represents a small fraction (hospital admitted and abnormal CT) (see Fig. 1), yet we see close to half 
have a mild or minimal TBI based on HISS classification. A partial explanation can be use of antithrombotic drugs. First, the risk of hematoma/hemorrhage is increased (Gaist et al. 2017; Gulati et al. 2018). Second, according to Scandinavian guidelines (Unden et al. 2013) CT imaging is indicated in patients with mild TBI using anticoagulants or are $\geq 65$ years and use antiplatelet therapy, thus identifying minor abnormalities on CT. Elderly who sustain a TBI more often have evidence of traumatic intracranial hemorrhage on CT (Andelic et al. 2008; Gardner et al. 2018). The most common intracranial CT abnormalities were tSAH, contusions and SDH, as in other studies (Steyerberg et al. 2019). Characteristics of younger patients were injuries of greater force, measured by trauma team activation, high-energy trauma and multitrauma.

High admittance rate to ICU suggests an aggressive treatment approach in initial phase in all ages. Nonetheless, survival in the older age groups was significantly lower. Higher mortality in older TBI patients is wellknown from the literature, yet this group has often been excluded in clinical TBI studies (Gaastra et al. 2016). Controversy exists if old patients benefit from aggressive treatment. However, research has demonstrated improved outcome with aggressive treatment in elderly (Herou et al. 2015; Lenell et al. 2019; Bus et al. 2019; Whitmore et al. 2012). It is worth noting that although pre-injury comorbidity was high in older age groups, about $60 \%$ of patients $80-89$ years still lived independently at home (Fig. 2b).

Studies from European trauma centers have reported a low threshold for ICU admission (Huijben et al. 2020; Volovici et al. 2019). Other studies question the necessity ICU admission or transfer to trauma center of low-risk TBI patients (Gates et al. 2017; Nishijima et al. 2011; Pruitt et al. 2017; Borczuk et al. 2019). A large proportion had a short LOS. Hence an issue for further investigation is whether we risk premature discharge for more severely injured patients who need specialized care, to be able to receive new patients. A part of this process would be a closer look at admissions to ICU and to trauma center for patients with mild TBI but not in need of intensive care, in light of current guidelines.

Studies on trauma populations describe trends towards increased admissions associated with warmer weather and summer months (northern temperate zone) (Kieffer et al. 2016; Ali and Willett 2015; Rising et al. 2006; Roislien et al. 2018; Bjarkø et al. 2019). However, our study did not identify significant variations between monthly admissions or TBI severity during the five-year period. On the contrary, at OUH TBI patients require a constant demand for acute treatment through the year. The admission rate does not just affect acute treatment, but includes the whole treatment chain. Consequently, there is a constant demand for qualified staff and beds in rehabilitation units as well.

We found a higher rate of admissions during the weekend, in accordance with other studies on trauma admissions (Kieffer et al. 2016; Stonko et al. 2018; Roislien et al. 2018; Bjarkø et al. 2019). The increased admission rate during afternoon, evening and at nighttime in weekends has also been found in other trauma centers (Stonko et al. 2018; Vaziri et al. 2007), both studies found penetrating trauma peaked around midnight - a few hours later than blunt trauma. Penetrating brain injuries is commonly caused by firearms, has high mortality, and has been reported to account for $12 \%$ of all TBI in the U.S. (Vakil and Singh 2017). Penetrating injury was an unusual trauma mechanism in our study $(<2 \%)$, thus not affecting time of admission.

Our results show that trauma activity is high when the hospital is mainly staffed for emergency care; particularly weekends are vulnerable in the execution of daily activities such as bedside visits. Knowing the high likelihood of interruptions and conflicts caused by new trauma; most of the planning and execution of elective inpatient treatment should be performed Monday to Friday between 07:00 and 17:00.

In the years after 2002, the trauma system at OUH was upgraded. As part of this process, neurosurgeons increased their all-hour presence and involvement in trauma patients. The result was increased survival in trauma patients, especially for patients with severe head/ neck injury (Sovik et al. 2014). Our study supports the necessity for all-hour presence of neurosurgeons, as severely injured TBI patients arrive at all hours.

In high-income countries, observed short term survival for severe TBI have varied between 70 and 55\% (Haller and Walder 2015), in accordance with our findings (69\%). A large European multicenter study on TBI reported an in-hospital survival of $85 \%$ and 6-month survival of $79 \%$ in patients admitted to ICU (Steyerberg et al. 2019); this was patients with moderate-severe TBI (median GCS 9, median age 49, with abnormal neuroimaging in $90 \%$ ). We found similar 30-day survival (78$90 \%$ ) for severe TBI in patients $<60$ years. Survival in the younger patients with severe TBI seems to have increased. However, survival in elderly patients decreased, and is in line with previous research (Gardner et al. 2018; Herou et al. 2015; Roe et al. 2013). This study illustrates the importance of including elderly with comorbidity in TBI research in order to increase the awareness of the implications this group has for clinical management and TBI outcome research. Further studies should emphasize on the associations between age, comorbidity and level of treatment, in order to ensure best possible outcome. 
Some study limitations need to be addressed. The study was performed at a single Level 1 trauma center with neurosurgical service in southeast region of Norway. We did not calculate the incidence of hospitaladmitted intracranial injuries in the region, as we did not have an overview of patients with minor intracranial injuries who were admitted and treated in general hospitals. Thus, the generalizability to patients treated in general hospitals, other geographical areas and countries with different health care organization is limited. Further, a well-known limitation of studies based on hospital medical records is missing data. Database coding errors can also be a limitation, but we have continuously searched and adjusted the database for inconsistency and coding errors. However, a large sample size, and prospective registration with no exclusion based on age, preinjury conditions or treatment are strengths of the study.

\section{Conclusion}

In TBI patients admitted to OUH with abnormal neuroimaging, the largest group is the late middle-aged and preinjury comorbidities are common. Fall is the major trauma mechanism. Patients are being admitted throughout the year, without seasonal differences. The case load is greatest when the hospital is mainly staffed for emergencies and care of critically ill inpatients, thus demanding an allhour presence of competent personnel. Overall burden for the trauma hospital is considerable, shown by high numbers and high admission rates to the ICU. Given the national population composition by an aging population, we have no reason to believe the number of patients will decrease in near future.

\section{Abbreviations}

ASA-PS: American Society of Anesthesiologists Physical Status Classification System; CT: Computed Tomography; EDH: Epidural hematoma; ER: Emergency room; GCS: Glasgow coma score; HISS: Head Injury Severity Score; ICU: Intensive care unit; IQR: Interquartile range; IVH: Intraventricular hemorrhage; LOS: Length of stay; MRI: Magnetic resonance imaging; MVC: Motor vehicle crash; OUH: Oslo University Hospital; SCl: Spinal cord injury; SD: Standard deviation; SDH: Acute subdural hematoma; TAl: Traumatic diffuse axonal injury; TBI: Traumatic Brain Injury; tSAH: Traumatic subarachnoid hemorrhage

\section{Acknowledgements}

Not applicable.

\section{Authors' contributions}

Conception and design: $\mathrm{CT}$ and EH. Data collection: $\mathrm{OS}, \mathrm{CT}$, EH. Analysis and drafting the manuscript: $C T, E H, N A$. All authors contributed substantially to the revision of manuscript and approved the final manuscript.

\section{Funding}

Founded by Department of Neurosurgery, Oslo University Hospital.

\section{Availability of data and materials}

The datasets generated and/or analyzed during the current study are not publicly available due to the sensitivity of the material, but are available from the corresponding author on reasonable request.

\section{Ethics approval and consent to participate}

The study was classified as a quality control study and was approved by OUH data protection officer. Consent to participate was waived.

\section{Consent for publication}

Not applicable.

\section{Competing interests}

The authors declare no conflict of interest.

\section{Author details}

'Department of Neurosurgery, Ullevål Hospital, Oslo University Hospital, P. O. Box 4956 Nydalen, N-0424 Oslo, Norway. ${ }^{2}$ Institute of Clinical Medicine, Faculty of Medicine, University of Oslo, Oslo, Norway. ${ }^{3}$ Department of Physical Medicine and Rehabilitation, Oslo University Hospital, Oslo, Norway. ${ }^{4}$ Institute of Health and Society, Research Centre for Habilitation and Rehabilitation Models and Services (CHARM), Faculty of Medicine, University of Oslo, Oslo, Norway. ${ }^{5}$ Department of Neuroradiology, Oslo University Hospital, Oslo, Norway.

Received: 23 April 2020 Accepted: 19 June 2020

Published online: 01 September 2020

\section{References}

Ali AM, Willett $\mathrm{K}$. What is the effect of the weather on trauma workload? A systematic review of the literature. Injury. 2015;46(6):945-53. https://doi.org/ 10.1016/j.injury.2015.03.016.

American Society of Anesthesiologists ASA Physical Status Classification System (2014) https://www.asahq.org/standards-and-guidelines/asa-physical-statusclassification-system. Accessed 11 Aug 2019.

Andelic N, Jerstad T, Sigurdardottir S, Schanke AK, Sandvik L, Roe C. Effects of acute substance use and pre-injury substance abuse on traumatic brain injury severity in adults admitted to a trauma Centre. J Trauma Management Outcomes. 2010;4:6. https://doi.org/10.1186/1752-2897-4-6.

Andelic N, Sigurdardottir S, Brunborg C, Roe C. Incidence of hospital-treated traumatic brain injury in the Oslo population. Neuroepidemiology. 2008;30(2): 120-8. https://doi.org/10.1159/000120025.

Astrand R, Rosenlund C, Unden J. Scandinavian guidelines for initial management of minor and moderate head trauma in children. BMC Med. 2016;14:33. https://doi.org/10.1186/s12916-016-0574-x.

Bakke E, Bogstrand ST, Normann PT, Ekeberg O, Bachs L. Influence of alcohol and other substances of abuse at the time of injury among patients in a Norwegian emergency department. BMC Emerg Med. 2016;16(1):20. https:// doi.org/10.1186/s12873-016-0085-2.

Berg CL, Blix HS, Fenne O, Furu K, Hjellvik V, Husabø KJ et al. (2017) Reseptregisteret 2012-2016 [the Norwegian prescription database 20122016] Legemiddelstatistikk 2017:2. Folkehelseinstituttet [Norwegian Institute of Public Health], Oslo, Norway.

Bjarkø W, Skandsen T, Moen KG, Gulati S, Helseth E, Nilsen TIL, et al. Time of injury and relation to alcohol intoxication in moderate-to-severe traumatic brain injury: a decade-long prospective study. World Neurosurg. 2019;122: e684-9. https://doi.org/10.1016/.wneu.2018.10.122.

Borczuk P, Van Ornam J, Yun BJ, Penn J, Pruitt P. Rapid discharge after Interfacility transfer for mild traumatic intracranial hemorrhage: frequency and associated factors. West J Emerg Med. 2019;20(2):307-15. https://doi.org/10.5811/ westjem.2018.12.39337.

Brain Trauma Foundation (2016) Guidelines for the Management of Severe TBI, 4th Ed. . https://braintrauma.org/guidelines/guidelines-for-the-managementof-severe-tbi-4th-ed\#/. Accessed 03 July 2019.

Bus S, Verbaan D, Kerklaan BJ, Sprengers MES, Vandertop WP, Stam J, et al. Do older patients with acute or subacute subdural hematoma benefit from surgery? Br J Neurosurg. 2019;33(1):51-7. https://doi.org/10.1080/02688697. 2018.1522418.

Centers for Disease Control and Prevention (2019) Surveillance Report of Traumatic Brain Injury-related Emergency Department Visits, Hospitalizations, and Deaths-United States, 2014. Centers for Disease Control and Prevention, U.S. Department of Health and Human Services.

Feigin VL, Theadom A, Barker-Collo S, Starkey NJ, McPherson K, Kahan M, et al. Incidence of traumatic brain injury in New Zealand: a population-based study. Lancet Neurol. 2013;12(1):53-64. https://doi.org/10.1016/s14744422(12)70262-4. 
Gaastra B, Longworth A, Matta B, Snelson C, Whitehouse T, Murphy N, et al. The ageing population is neglected in research studies of traumatic brain injury. $\mathrm{Br}$ J Neurosurg. 2016;30(2):221-6. https://doi.org/10.3109/02688697.2015.1119240.

Gaist D, Garcia Rodriguez LA, Hellfritzsch M, Poulsen FR, Halle B, Hallas J, et al. Association of Antithrombotic Drug use with Subdural Hematoma Risk. JAMA. 2017:317(8):836-46. https://doi.org/10.1001/jama.2017.0639.

Gale SC, Peters J, Murry JS, Crystal JS, Dombrovskiy VY. Injury patterns and outcomes in late middle age (55-65): The intersecting comorbidity with high-risk activity - A retrospective cohort study. Ann Med Surg (2012). 2018; 27:22-5. https://doi.org/10.1016/j.amsu.2018.01.005.

Gardner RC, Dams-O'Connor K, Morrissey MR, Manley GT. Geriatric traumatic brain injury: epidemiology, outcomes, knowledge gaps, and future directions. J Neurotrauma. 2018. https://doi.org/10.1089/neu.2017.5371.

Gates M, Mallory G, Planchard R, Nothdurft G, Graffeo C, Atkinson J. Triage patterns of traumatic subarachnoid hemorrhage: is referral to a tertiary care center necessary? World Neurosurg. 2017;100:417-23. https://doi.org/10.1016/ j.wneu.2017.01.046.

Gulati S, Solheim O, Carlsen SM, Oie LR, Jensberg H, Gulati AM, et al. Risk of intracranial hemorrhage $(\mathrm{RICH})$ in users of oral antithrombotic drugs: Nationwide pharmacoepidemiological study. PLoS One. 2018;13(8):e0202575. https://doi.org/10.1371/journal.pone.0202575.

Haller CS, Walder B. Severe neurotrauma in Switzerland: have short-term outcomes improved? Swiss Med Wkly. 2015;145:w14177. https://doi.org/10. 4414/smw.2015.14177.

Harr ME, Heskestad B, Ingebrigtsen T, Romner B, Ronning P, Helseth E. Alcohol consumption, blood alcohol concentration level and guideline compliance in hospital referred patients with minimal, mild and moderate head injuries. Scand J Trauma Resusc Emerg Med. 2011;19:25. https://doi.org/10.1186/17577241-19-25.

Helse og omsorgsdepartementet (2017) Kart over Norges akuttsykehus. Regjerningen. https://www.regjeringen.no/no/tema/helse-og-omsorg/ sykehus/nasjonal-helse\%2D\%2Dog-sykehusplan2/kart-over-norgesakuttsykehus/id2551362/. Accessed 19 Dec 2018.

Herou E, Romner B, Tomasevic G. Acute traumatic brain injury: mortality in the elderly. World Neurosurg. 2015;83(6):996-1001. https://doi.org/10.1016/j. wneu.2015.02.023.

Heskestad B, Baardsen R, Helseth E, Romner B, Waterloo K, Ingebrigtsen T. Incidence of hospital referred head injuries in Norway: a population based survey from the Stavanger region. Scand J Trauma Resusc Emerg Med. 2009; 17:6. https://doi.org/10.1186/1757-7241-17-6.

Huijben JA, Wiegers EJA, Lingsma HF, Citerio G, Maas AIR, Menon DK et al. Changing care pathways and between-center practice variations in intensive care for traumatic brain injury across Europe: a CENTER-TBI analysis. Intensive Care Med. 2020:https://doi.org/10.1007/s00134-00020-05965-z. doi:https://doi. org/10.1007/s00134-020-05965-z.

Injuries in Norway. In: Public health report - Health status in Norway [online document]. Norwegian Institute of public health (2017) https://www.fhi.no/ en/op/hin/injuries/injuries-in-Norway/. Accessed 27 Nov 2019.

Iverson GL, Lange RT, Waljas M, Liimatainen S, Dastidar P, Hartikainen KM, et al. Outcome from complicated versus uncomplicated mild traumatic brain injury. Rehabilitation Res Practice. 2012;2012:415740. https://doi.org/10.1155/ 2012/415740

James SL, Theadom A, Ellenbogen RG, Bannick MS, Montjoy-Venning W, Lucchesi $L R$, et al. Global, regional, and national burden of traumatic brain injury and spinal cord injury, 1990-2016: a systematic analysis for the global burden of disease study 2016. Lancet Neurol. 2019;18(1):56-87.

Julien J, Alsideiri G, Marcoux J, Hasen M, Correa JA, Feyz M, et al. Antithrombotic agents intake prior to injury does not affect outcome after a traumatic brain injury in hospitalized elderly patients. J Clin Neurosci. 2017;38:122-5. https:// doi.org/10.1016/j.jocn.2016.12.032

Kieffer WK, Michalik DV, Gallagher K, McFadyen I, Bernard J, Rogers BA. Temporal variation in major trauma admissions. Ann R Coll Surg Engl. 2016;98(2):12837. https://doi.org/10.1308/rcsann.2016.0040.

Koskinen S, Alaranta H. Traumatic brain injury in Finland 1991-2005: a nationwide register study of hospitalized and fatal TBI. Brain Inj. 2008;22(3):205-14. https://doi.org/10.1080/02699050801938975.

Lenell S, Nyholm L, Lewen A, Enblad P. Clinical outcome and prognostic factors in elderly traumatic brain injury patients receiving neurointensive care. Acta Neurochir. 2019;161(6):1243-54. https://doi.org/10.1007/s00701-019-03893-6.

Maas Al, Hukkelhoven CW, Marshall LF, Steyerberg EW. Prediction of outcome in traumatic brain injury with computed tomographic characteristics: a comparison between the computed tomographic classification and combinations of computed tomographic predictors. Neurosurgery. 2005; 57(6):1173-82 discussion 1173-1182.

Menon DK, Schwab K, Wright DW, Maas Al. Position statement: definition of traumatic brain injury. Arch Phys Med Rehabil. 2010;91(11):1637-40. https:// doi.org/10.1016/j.apmr.2010.05.017.

Narum S, Brors O, Stokland O, Kringen MK. Mortality among head trauma patients taking preinjury antithrombotic agents: a retrospective cohort analysis from a level 1 trauma Centre. BMC Emerg Med. 2016;16(1):29. https://doi.org/10.1186/s12873-016-0094-1.

National Institute for Health and Care Excellence (2014) Head injury: assessment and early management (NICE Clinical guideline [CG176]). https://www.nice. org.uk/guidance/cg176. Accessed 29 Oct 2019.

Nishijima DK, Sena MJ, Holmes JF. Identification of low-risk patients with traumatic brain injury and intracranial hemorrhage who do not need intensive care unit admission. J Trauma. 2011;70(6):E101-7. https://doi.org/10. 1097/TA.0b013e3181e88bcb.

Nyholm L, Howells T, Enblad P, Lewen A. Introduction of the Uppsala traumatic brain injury register for regular surveillance of patient characteristics and neurointensive care management including secondary insult quantification and clinical outcome. Ups J Med Sci. 2013;118(3):169-80. https://doi.org/10. 3109/03009734.2013.806616.

Owens PW, Lynch NP, O'Leary DP, Lowery AJ, Kerin MJ. Six-year review of traumatic brain injury in a regional trauma unit: demographics, contributing factors and service provision in Ireland. Brain Inj. 2018;32(7):900-6. https://doi. org/10.1080/02699052.2018.1466366.

Pandor A, Goodacre S, Harnan S, Holmes M, Pickering A, Fitzgerald P, et al. Diagnostic management strategies for adults and children with minor head injury: a systematic review and an economic evaluation. Health Technol Assess. 2011;15(27):1-202. https://doi.org/10.3310/hta15270.

Pedersen K, Fahlstedt M, Jacobsson A, Kleiven S, von Holst H. A National Survey of traumatic brain injuries admitted to hospitals in Sweden from 1987 to 2010. Neuroepidemiology. 2015;45(1):20-7. https://doi.org/10.1159/ 000381780.

Peeters G, Cooper R, Tooth L, van Schoor NM, Kenny RA. A comprehensive assessment of risk factors for falls in middle-aged adults: co-ordinated analyses of cohort studies in four countries. Osteoporos Int. 2019. https://doi. org/10.1007/s00198-019-05034-2.

Peeters W, Majdan M, Brazinova A, Nieboer D, Maas AIR. Changing epidemiological patterns in traumatic brain injury: a longitudinal hospitalbased study in Belgium. Neuroepidemiology. 2017;48(1-2):63-70. https://doi. org/10.1159/000471877.

Peeters W, van den Brande R, Polinder S, Brazinova A, Steyerberg EW, Lingsma $H F$, et al. Epidemiology of traumatic brain injury in Europe. Acta Neurochir. 2015;157(10):1683-96. https://doi.org/10.1007/s00701-015-2512-7.

Pruitt P, Penn J, Peak D, Borczuk P. Identifying patients with mild traumatic intracranial hemorrhage at low risk of decompensation who are safe for ED observation. Am J Emerg Med. 2017;35(2):255-9. https://doi.org/10.1016/j. ajem.2016.10.064

Regional Committees for Medical and Health Research Ethics (REC) (2012) Examples of activities that do not require approval from REC. https:// helseforskning.etikkom.no/reglerogrutiner/soknadsplikt/sokerikkerek?p_dim= 34999\&_ikbLanguageCode=us. Accessed 6 July 2018.

Rickels E, von Wild K, Wenzlaff P. Head injury in Germany: a population-based prospective study on epidemiology, causes, treatment and outcome of all degrees of head-injury severity in two distinct areas. Brain Inj. 2010;24(12): 1491-504. https://doi.org/10.3109/02699052.2010.498006.

Rising WR, O'Daniel JA, Roberts CS. Correlating weather and trauma admissions at a level I trauma center. J Trauma. 2006;60(5):1096-100. https://doi.org/10. 1097/01.ta.0000197435.82141.27.

Robertson A, Giannoudis PV. Excessive volume of trauma workload out of hours: is it really true? Injury. 2004;35(9):864-8. https://doi.org/10.1016/j.injury.2003. 10.022 .

Roe C, Skandsen T, Anke A, Ader T, Vik A, Lund SB, et al. Severe traumatic brain injury in Norway: impact of age on outcome. J Rehabil Med. 2013;45(8):73440. https://doi.org/10.2340/16501977-1198.

Roislien J, Sovik S, Eken T. Seasonality in trauma admissions - are daylight and weather variables better predictors than general cyclic effects? PLoS One. 2018;13(2):e0192568. https://doi.org/10.1371/journal.pone.0192568.

Ronning P, Helseth E, Skaga NO, Stavem K, Langmoen IA. The effect of ICP monitoring in severe traumatic brain injury: a propensity score-weighted and 
adjusted regression approach. J Neurosurg. 2018:1-9. https://doi.org/10.3171/ 2018.7.jns18270.

Roozenbeek B, Maas Al, Menon DK. Changing patterns in the epidemiology of traumatic brain injury. Nat Rev Neurol. 2013;9(4):231-6. https://doi.org/10. 1038/nrneurol.2013.22.

Sollid S, Sundstrom T, Kock-Jensen C, Juul N, Eskesen V, Bellander BM, et al. Scandinavian guidelines for prehospital management of severe traumatic brain injury. Tidsskr Nor Laegeforen. 2008;128(13):1524-7.

Sovik S, Skaga NO, Hanoa R, Eken T. Sudden survival improvement in critical neurotrauma: an exploratory analysis using a stratified statistical process control technique. Injury. 2014;45(11):1722-30. https://doi.org/10.1016/j.injury. 2014.05.038.

Statistics Norway Statbank - Population. (n.d.) https://www.ssb.no/en/statbank/ table/01222. Accessed 29 Apr 2020.

Stein SC, Spettell C. The head injury severity scale (HISS): a practical classification of closed-head injury. Brain Inj. 1995;9(5):437-44.

Steyerberg EW, Wiegers E, Sewalt C, Buki A, Citerio G, De Keyser V, et al. Casemix, care pathways, and outcomes in patients with traumatic brain injury in CENTER-TBI: a European prospective, multicentre, longitudinal, cohort study. Lancet Neurol. 2019;18(10):923-34. https://doi.org/10.1016/s14744422(19)30232-7.

Stonko DP, Dennis BM, Callcut RA, Betzold RD, Smith MC, Medvecz AJ, et al. Identifying temporal patterns in trauma admissions: informing resource allocation. PLoS One. 2018;13(12):e0207766. https://doi.org/10.1371/journal. pone.0207766.

Unden J, Ingebrigtsen T, Romner B. Scandinavian guidelines for initia management of minimal, mild and moderate head injuries in adults: an evidence and consensus-based update. BMC Med. 2013;11:50. https://doi. org/10.1186/1741-7015-11-50.

Vakil MT, Singh AK. A review of penetrating brain trauma: epidemiology, pathophysiology, imaging assessment, complications, and treatment. Emerg Radiol. 2017;24(3):301-9. https://doi.org/10.1007/s10140-016-1477-z.

Vaziri K, Roland JC, Robinson L, Fakhry SM. Optimizing physician staffing and resource allocation: sine-wave variation in hourly trauma admission volume. J Trauma. 2007;62(3):610-4. https://doi.org/10.1097/TA.0b013e31803245c7.

Volovici V, Ercole A, Citerio G, Stocchetti N, Haitsma IK, Huijben JA, et al. Intensive care admission criteria for traumatic brain injury patients across Europe. J Crit Care. 2019:49:158-61. https://doi.org/10.1016/j.jcrc.2018.11.002.

Whitmore RG, Thawani JP, Grady MS, Levine JM, Sanborn MR, Stein SC. Is aggressive treatment of traumatic brain injury cost-effective? J Neurosurg. 2012;116(5):1106-13. https://doi.org/10.3171/2012.1.Jns11962.

Williams DH, Levin HS, Eisenberg HM. Mild head injury classification. Neurosurgery. 1990;27(3):422-8. https://doi.org/10.1097/00006123-19900900000014.

\section{Publisher's Note}

Springer Nature remains neutral with regard to jurisdictional claims in published maps and institutional affiliations.

Ready to submit your research? Choose BMC and benefit from:

- fast, convenient online submission

- thorough peer review by experienced researchers in your field

- rapid publication on acceptance

- support for research data, including large and complex data types

- gold Open Access which fosters wider collaboration and increased citations

- maximum visibility for your research: over $100 \mathrm{M}$ website views per year

At BMC, research is always in progress.

Learn more biomedcentral.com/submissions 